Sharif University of Technology
Scientia Iranica
SCIENTIA
IRAN I CA
Transactions A: Civil Engineering
www.scientiairanica.com

\title{
Effect of marble dust on the corrosion resistance of glass fiber reinforced mortars
}

\author{
O. Keleştemur* and S. Yildız \\ Department of Civil Engineering, Faculty of Technology, Firat University, 23119, Elazig, Turkey.
}

Received 14 September 2015; received in revised form 11 June 2015; accepted 6 September 2015

\section{KEYWORDS}

Corrosion;

Mortar;

Glass fiber;

Marble dust;

Microstructure.

\begin{abstract}
In this study, mechanical and physical properties of cement mortars containing marble dust and glass fiber in various combinations were investigated, in addition to analyzing the corrosion behavior of reinforcing steels embedded in these mortars. To this end, cement mortars containing glass fiber $\left(0 \mathrm{~kg} / \mathrm{m}^{3}, 0.25 \mathrm{~kg} / \mathrm{m}^{3}, 0.50 \mathrm{~kg} / \mathrm{m}^{3}\right.$, and $0.75 \mathrm{~kg} / \mathrm{m}^{3}$ ) were prepared. Besides, with the purpose of determining effect of marble dust addition on the corrosion resistance of the glass fiber reinforced mortars, marble dust was added to all series by replacing with filler sand at proportions of $0 \%, 10 \%, 30 \%$, and $50 \%$ by volume. Corrosion studies were carried out in two stages. Firstly, corrosion potential of reinforcing steels in the mortars was measured every day for a period of 150 days based on the ASTM C-876 standard. Secondly, cathodic polarization values of the steels were obtained by using the Tafel extrapolation technique and, subsequently, corrosion current densities were determined. Thanks to the study, it was observed that a decrease in the corrosion resistance of the mortars had taken place as a result of glass fiber addition. But, it was determined that with the addition of marble dust into the mortars, corrosion resistance of the specimens was significantly increased.
\end{abstract}

(C) 2016 Sharif University of Technology. All rights reserved.

\section{Introduction}

Leaving the waste materials in the environment can directly cause environmental problems. In general, the industry of dimensional stone marble has contributed to the development of major environmental problems due to waste generation at various stages of mining and processing operations [1]. Marble blocks are cut into smaller blocks in order to give the desired smooth shape. During the cutting process, about $25 \%$ marble mass is lost in the form of dust. In Turkey, marble dust is settled by sedimentation and then dumped away, which results in environmental pollution and also causes forming dust in the summer threatening

*. Corresponding author. Tel.: +90 4242370000; Fax: +904242367064

E-mail addresses: okelestemur@firat.edu.tr(O.

Keleştemur); syildiz@firat.edu.tr (S.Yıldız) both agriculture and public health. Therefore, use of the marble dust in various sectors, especially the construction, agriculture, glass, and paper industries, will help to protect the environment [2].

Many researchers were recently interested in studying the possibility of re-using the waste marble dust in useful industries, especially with regard to the building and construction materials such as cement, concrete, and brick blocks [1]. The effect of marble dust on the mechanical and physical properties of cement based materials was investigated; most of the research showed positive results and benefits [3-9]. But, not a single study has been encountered on corrosion performance of cement mortars prepared by replacing very fine sand with waste marble dust in the open literature.

Glass fibers are a type of high-strength fiber materials and have many application areas in construction sector. Glass fibers commonly use composite materials 
in concrete owing to their great tensile strength and module; glass fibers have great potential to be used in concrete due to their superior characteristics in terms of high stiffness, low density and water absorption, high tensile strength, corrosion resistance, etc. [10-13].

Reinforced concrete is the most widely used construction material all over the world [14]. The use of reinforced concrete structures is based on the principle that concrete is an ideal environment for reinforcing steel. The high alkalinity of concrete causes the formation of a saturated hydrated iron oxide passivating film on the surface of the steel, which provides good protection against corrosion. However, depassivation may be occurred by carbonation of the concrete cover or by the presence of chloride salts, thus initiating expansive corrosion of the steel, causing eventual damage to the surrounding concrete [15]. A good-quality concrete with low permeability is a primary corrosion control measure for reinforcing steel embedded in concrete. Previous studies have shown that use of marble dust as sand replacement in concrete may reduce its permeability $[5,7]$.

The main objective of this study was to investigate the effect of marble dust addition on corrosion behavior of reinforcing steels embedded in glass fiber reinforced cement mortar specimens. Furthermore, the effect of marble dust on the mechanical and physical properties of the glass fiber reinforced mortar specimens was also investigated.

\section{Materials and methods}

Total of sixteen series of mortar specimens including the control specimen were prepared in order to examine the corrosion behavior of reinforcing steels embedded in mortar specimens with marble dust and glass fiber in various combinations. For the corrosion tests, a total of eighty pieces of mortar specimens were obtained, with five specimens being taken from each series.

\subsection{Preparing electrodes}

As an electrode, the SAE1010 steel bar produced by Ereğli Iron and Steel Factories in Turkey was selected for this study. The as-received material was in the form of a hot-rolled bar $12 \mathrm{~mm}$ in diameter. The chemical composition of the electrode is given in Table 1.

160 pieces of steel bars in $120 \mathrm{~mm}$ of length were cut out from the as-received material and their surfaces were mechanically cleaned. Then, specimen surfaces were polished with 1200 mesh sandpaper. Polished surfaces were cleaned with ethyl alcohol. Surface areas

Table 1. Chemical composition of the steel (\% wt.).

\begin{tabular}{cccccc}
\hline $\mathbf{C}$ & $\mathbf{M n}$ & $\mathbf{S i}$ & $\mathbf{P}$ & $\mathbf{S}$ & $\mathbf{F e}$ \\
\hline 0.17 & 0.250 & 0.050 & 0.005 & 0.050 & Balance \\
\hline
\end{tabular}

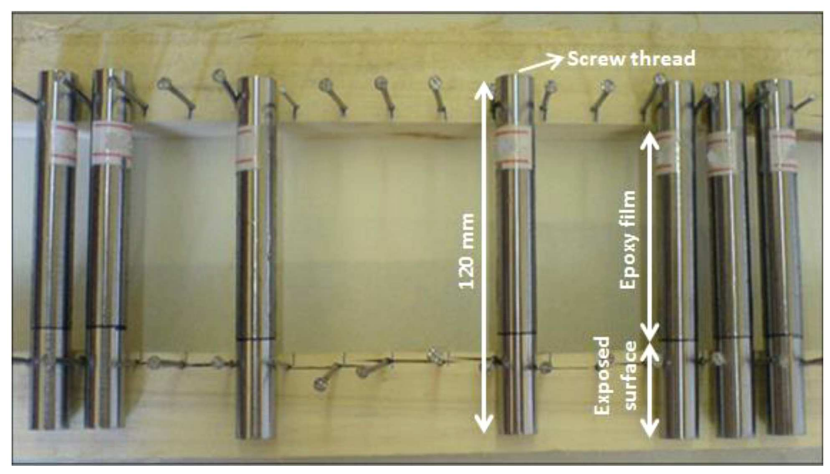

Figure 1. Electrodes used in corrosion experiments.

$\left(10 \mathrm{~cm}^{2}\right)$ were kept open in the tips of electrodes, which would be embedded in the mortar. Screw thread was machined at the other ends of the electrodes and cables were connected to these ends in order to make measurements during the experiment in an easier way. The remaining sections of the steel electrodes were protected against external effects by covering them with epoxy resin at first and then with polyethylene. Figure 1 shows the electrodes used in the corrosion experiments.

\subsection{Preparing mortar specimens for the corrosion tests}

$100 \times 100 \times 200 \mathrm{~mm}$ mortar specimens were prepared for the corrosion experiments, in which the electrodes prepared in advance were embedded.

Commercial grade ASTM Type I Portland cement, which is produced in Turkey as CEM I Portland cement, was used in the preparation of all cement mortar specimens that were employed in the experiments within the scope of this study.

The marble sludge was obtained in wet form as an industrial by-product directly from the deposits of marble factories, which forms during the sawing, shaping, and polishing processes of the marbles in the Elazig province of Turkey. The marble sludge was dried in an oven at approximately $50^{\circ} \mathrm{C}$ for $48 \mathrm{~h}$ before the preparation of the cement mortar specimens. The dried material was passed through $0.25 \mathrm{~mm}$ sieve and finally the marble dust was obtained to be used in the cement mortar specimens as very fine sand. The chemical properties of the marble dust and cement used in the experiments are presented in Table 2 .

High-quality river sand was used as aggregate, which is widely employed in mortar production. Maximum grain size of aggregate was $4 \mathrm{~mm}$. The density of the river sand was $2690 \mathrm{~kg} / \mathrm{m}^{3}$. Various proportions $(0 \%, 10 \%, 30 \%$ and $50 \%$, by volume) of the very fine sand (passing through $0.25 \mathrm{~mm}$ sieve) were replaced with waste marble dust. The grain size distributions of very fine sand and waste marble dust are shown in Figure 2.

The glass fibers were circular straight fibers ob- 
Table 2. Chemical compositions of the cement and marble dusts.

\begin{tabular}{ccc}
\hline $\begin{array}{c}\text { Oxide compounds } \\
(\text { mass \%) }\end{array}$ & CEM I 42.5 N & $\begin{array}{c}\text { Marble } \\
\text { dust }\end{array}$ \\
\hline $\mathrm{SiO}_{2}$ & 21.12 & 12.67 \\
$\mathrm{Al}_{2} \mathrm{O}_{3}$ & 5.62 & 1.07 \\
$\mathrm{Fe}_{2} \mathrm{O}_{3}$ & 3.24 & 3.79 \\
$\mathrm{CaO}$ & 62.94 & 40.44 \\
$\mathrm{MgO}$ & 2.73 & 10.84 \\
Density $\left(\mathrm{g} / \mathrm{cm}^{3}\right)$ & 3.10 & 2.78 \\
\hline
\end{tabular}

tained from Camelsan. The properties of the glass fiber used in the study are given in Table 3 .

The mixture designs of all the cement mortar groups are presented in Table 4. A superplasticizer (SP) was used to improve workability of the mortar mixes. Modified polycarboxilate based superplasticizer, obtained from SIKA, was used as $1 \%$ of cement weight. Regular tap water was used as the mixing water during the preparation of the mortar specimens.

The cement mortar specimens were kept in molds for duration of $24 \mathrm{~h}$ at room temperature of about $20 \pm$ $2{ }^{\circ} \mathrm{C}$. After demolding, these specimens were cured for seven days at $25^{\circ} \mathrm{C}$ in $100 \%$ relative humidity, before

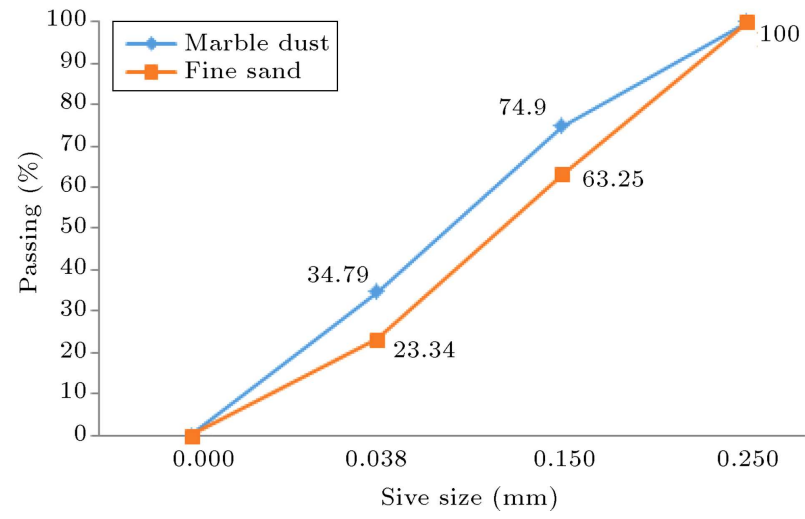

Figure 2. Grain size distributions of the very fine sand and marble dust.

getting partially submerged in a $3 \% \mathrm{NaCl}$ solution to induce a corrosive environment.

\subsection{Corrosion tests}

Corrosion tests were conducted in two stages. In the first stage, the corrosion potential of reinforcing steels embedded in the mortar specimens was measured every day for a period of 150 days in accordance with ASTM C876 method [16]. Saturated copper/copper sulfate $\left(\mathrm{Cu} / \mathrm{CuSO}_{4}\right)$ was used as the reference electrode, and a high impedance voltmeter was used as the mea-

Table 3. Properties of the glass fiber used in the experiments.

\begin{tabular}{cccccc}
\hline Color & $\begin{array}{c}\text { Length } \\
(\mathbf{m m})\end{array}$ & $\begin{array}{c}\text { Diameter } \\
(\boldsymbol{\mu m})\end{array}$ & $\begin{array}{c}\text { Density } \\
\left(\mathrm{g} / \mathbf{c m}^{3}\right)\end{array}$ & $\begin{array}{c}\text { Young's } \\
\text { Modulus (MPa) }\end{array}$ & $\begin{array}{c}\text { Tensile } \\
\text { Strength (MPa) }\end{array}$ \\
\hline White & 6 & 13 & 2.68 & 72000 & 1700 \\
\hline
\end{tabular}

Table 4. Details of the cement mortar mixes $\left(\mathrm{kg} / \mathrm{m}^{3}\right)$.

\begin{tabular}{clccccccc}
\hline $\begin{array}{c}\text { Exp. } \\
\text { no }\end{array}$ & $\begin{array}{l}\text { Designation } \\
\text { of mixtures }\end{array}$ & $\begin{array}{c}\text { Fiber } \\
\text { glass }\end{array}$ & $\begin{array}{c}\text { Marble } \\
\text { dust }\end{array}$ & $\begin{array}{c}\text { Aggregate } \\
(\mathbf{0}-\mathbf{0 . 2 5})\end{array}$ & $\begin{array}{c}\text { Aggregate } \\
(\mathbf{0 . 2 5}-\mathbf{4})\end{array}$ & Water & Cement & SP \\
\hline 1 & C (GF0-MD0) & - & - & 407 & 1253.8 & 221.4 & 450 & 4.45 \\
2 & GF0-MD10 & - & 38.63 & 367 & 1253.8 & 221.4 & 450 & 4.45 \\
3 & GF0-MD30 & - & 115.9 & 285.2 & 1253.8 & 222.8 & 450 & 4.45 \\
4 & GF0-MD50 & - & 193.12 & 203.6 & 1253.8 & 222.8 & 450 & 4.45 \\
5 & GF0.25-MD0 & 0.25 & - & 407 & 1253.8 & 221.4 & 450 & 4.45 \\
6 & GF0.25-MD10 & 0.25 & 38.63 & 367 & 1253.8 & 221.4 & 450 & 4.45 \\
7 & GF0.25-MD30 & 0.25 & 115.9 & 285.2 & 1253.8 & 222.8 & 450 & 4.45 \\
8 & GF0.25-MD50 & 0.25 & 193.12 & 203.6 & 1253.8 & 222.8 & 450 & 4.45 \\
9 & GF0.50-MD0 & 0.50 & - & 407 & 1253.8 & 221.4 & 450 & 4.45 \\
10 & GF0.50-MD10 & 0.50 & 38.63 & 367 & 1253.8 & 221.4 & 450 & 4.45 \\
11 & GF0.50-MD30 & 0.50 & 115.9 & 285.2 & 1253.8 & 222.8 & 450 & 4.45 \\
12 & GF0.50-MD50 & 0.50 & 193.12 & 203.6 & 1253.8 & 222.8 & 450 & 4.45 \\
13 & GF0.75-MD0 & 0.75 & - & 407 & 1253.8 & 221.4 & 450 & 4.45 \\
14 & GF0.75-MD10 & 0.75 & 38.63 & 367 & 1253.8 & 221.4 & 450 & 4.45 \\
15 & GF0.75-MD30 & 0.75 & 115.9 & 285.2 & 1253.8 & 222.8 & 450 & 4.45 \\
16 & GF0.75-MD50 & 0.75 & 193.12 & 203.6 & 1253.8 & 222.8 & 450 & 4.45 \\
\hline
\end{tabular}


Table 5. Estimation of corrosion probability as determined by half-cell potential test.

\begin{tabular}{cc}
\hline Potential $(\mathbf{m V}) \mathbf{( C S E )}$ & Probability of the presence of active corrosion \\
\hline$>-200$ & The probability for corrosion is very low \\
$-200 \sim-350$ & Uncertain \\
$<-350$ & The probability for corrosion is very high \\
\hline
\end{tabular}

surement device in corrosion potential measurements. Changes in corrosion potentials versus time were indicated in graphs in order to determine whether the reinforcing steel bar was active or passive. Recommendations on evaluation of potential measurement results in ASTM C876 experiment method are specified in Table $5[17,18]$.

In the second stage, the anodic and cathodic polarization values of the electrodes in the mortars were obtained by using the galvanostatic technique and then the corrosion current densities were determined with the aid of cathodic polarization curves. The Tafel extrapolation technique (TP) was used to determine the polarization curves. The TP is electrochemical method for calculating corrosion rate based on intensity of the corrosion current $\left(I_{\text {corr }}\right)$ and the Tafel slopes. This technique is based upon application of either steady fixed levels of current followed by monitoring of the potential (galvanostatic) or application of a specific potential followed by monitoring of the current (potentiostatic). The galvanostatic method was used in this study. Sufficient Tafel slopes were obtained by applying constant current densities from $0.01 \mu \mathrm{A} / \mathrm{cm}^{2}$ to $20 \mu \mathrm{A} / \mathrm{cm}^{2}$. In this technique, generally, cathodic data is preferred since it is easier to be used for experimental measurement. Furthermore, often, anodic curves may not exhibit linear behavior near $E_{\text {corr }}$. Therefore, corrosion current densities of the reinforcing steels embedded in the mortar specimens were determined by using cathodic polarization curves. The corrosion current density, $I_{\text {corr }}$, was obtained from the Tafel plot by extrapolating the linear portion of the cathodic curve to $E_{\text {corr }}$.

The experimental setup used for the application of galvanostatic method is shown in Figure 3. In this circuit, the electrode that is connected to the positive terminal is the anode and the other that is connected to the negative terminal of the DC power source, which supplies a fixed voltage of $20 \mathrm{~V}$ DC to the system, is the cathode. The same material (SAE1010 steel bar) has been used for anode and cathode electrodes.

\subsection{Hardened concrete experiments}

The corrosion behaviors of the mortar specimens consisting of marble dust and fiber glass at various proportions as well as their mechanical and physical properties like compressive strength, flexural strength, and porosity were investigated. Furthermore, sorptivity measurement was also conducted on the mortar

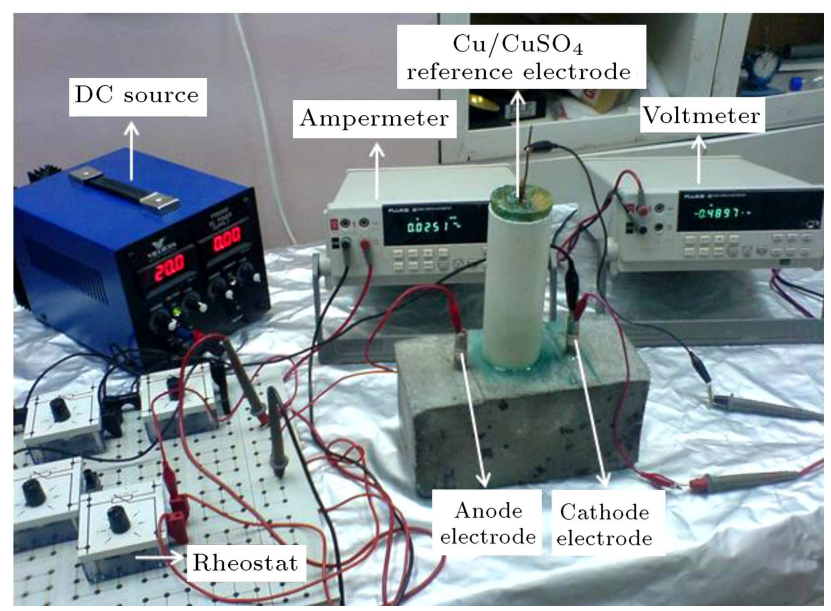

Figure 3. The experimental setup used for the application of galvanostatic technique.

specimens. The data was interpreted together with the corrosion rate of steels embedded in these mortar specimens.

The mixtures were cast from the same batch into prismatic $(40 \times 40 \times 160 \mathrm{~mm})$ and cubic $(50 \times$ $50 \times 50 \mathrm{~mm})$ steel molds for flexural and compressive strength experiments, respectively. The specimens were kept in the molds for $24 \mathrm{~h}$ at room temperature of about $20 \pm 2^{\circ} \mathrm{C}$. After demolding, these specimens were cured in lime saturated water for 28 days.

Five specimens from each series were used to determine the compressive and flexural strengths at 28 days according to TS EN 196-1. The compression loads were applied at rates of $2400 \mathrm{~N} / \mathrm{s}$ and $50 \mathrm{~N} / \mathrm{s}$ to determine the compressive and flexural strengths of the mortar specimens, respectively. For flexural strength of the mortars, the specimens were loaded from their mid span and the clear distance between simple supports was $120 \mathrm{~mm}$.

The porosity of the cement mortar specimens was measured applying the vacuum-saturation technique. The porosity measurements were carried out on slices of $68 \mathrm{~mm}$ diameter cores cut out from the center of $100 \mathrm{~mm}$ cubes (parallel to the casting direction). The specimens were dried in an oven at $100 \pm 5^{\circ} \mathrm{C}$ until constant mass was achieved and they were then placed in a desiccator under vacuum for at least 3 hours after which the desiccator was filled with deaired distilled water. The porosity value for each mortar specimen was calculated through Eq. (1). This method for measuring the porosity has previously been 
reported [19-21].

$$
P=\frac{\left(W_{\text {sat }}-W_{\text {dry }}\right)}{\left(W_{\text {sat }}-W_{\text {wat }}\right)} 100
$$

where, $P$ stands for vacuum saturation porosity (\%); $W_{\text {sat }}$ weight in air of saturated specimen; $W_{\text {wat }}$ weight in water of saturated specimen; and $W_{\text {dry }}$ weight of oven-dried specimen.

Five test specimens for sorptivity measurement were prepared for each mixture. The sorptivity measurements were carried out on $50 \mathrm{~mm}$ cube specimens. Measurements of capillary sorption were carried out using specimens pre-conditioned in the oven at about $50^{\circ} \mathrm{C}$ until constant mass was achieved. Then, the mortar specimens were cooled down to room temperature. The side surface of each specimen was sealed with paraffin to achieve unidirectional flow. The end of the specimen that would not be exposed to water was sealed using a loosely attached plastic bag to control evaporation from this surface. The plastic bag was secured using an elastic band. Rods supports were placed at the bottom of the pan and the pan was filled with tap water so that the water level was $5 \mathrm{~mm}$ above the top of the rods supports. The water level in the pan was maintained $5 \mathrm{~mm}$ above the top of the support for the duration of the tests. As shown in Figure 4, the test surface of the specimen was placed on the rods supports. At certain times, the mass of the mortar specimens was measured using a balance; then, the amount of absorbed water was calculated and normalized with respect to the cross-section area of the specimens subjected to the water at various times such as $0,5,10,20,30,60,180,360$, and $1440 \mathrm{~min}$. The capillary absorption coefficient $(k)$ was obtained by using the following equation:

$$
\frac{Q}{A}=k \sqrt{t}
$$

where $Q$ stands for the amount of water absorbed

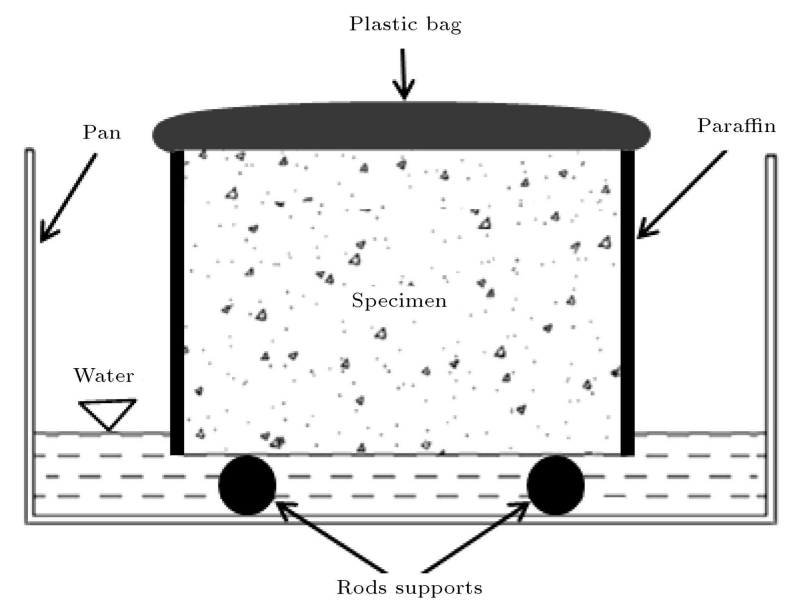

Figure 4. Schematic demonstration for the measurement of water capillary sorption. $\left(\mathrm{cm}^{3}\right) ; A$ the cross-section of specimen that was in contact with water $\left(\mathrm{cm}^{2}\right) ; t$ time $(\mathrm{s})$; and $k$ the sorptivity coefficient of the specimen $\left(\mathrm{cm} / \mathrm{s}^{1 / 2}\right)$. To determine the sorptivity coefficient, $Q / A$ was plotted against the square root of time $(\sqrt{t})$, and then, $k$ was calculated from the slope of the linear relation between $Q / A$ and $\sqrt{t}$. This method of measuring the capillary absorption has been used in many previous studies [21$25]$.

The microscopic analyses of the cement mortar specimens were performed at the Electron Microscopy Laboratory of Firat University using a Jeol JSM7001F scanning electron microscope.

\section{Results and discussion}

\subsection{Results of mechanical and physical experiments conducted on hardened mortars}

The data obtained through mechanical and physical experiments conducted on the hardened mortar specimens is presented in Table 6 .

The results presented in Table 6 indicated that the compressive and flexural strengths of the cement mortars increased with increasing the percentage of marble dust. Moreover, in contrast to marble dust effect, the use of glass fiber in the mortar specimens with and without marble dust increased the flexural strength but decreased the compressive strength of the mortars.

Table 6 demonstrates that compressive strength of the mortar specimens decreased depending on the increase in the amount of glass fiber. This outcome is expected because glass fibers have more ductile structure as per the cement matrix and aggregate when the glass fibers are added to the specimens; they cause discontinuity in the cement matrix. Thus, the compressive strength of the mortars decreases as the amount of glass fiber content increases. Similar relationships have also been reported by the studies appearing in $[26,27]$. Figure 5 shows the SEM (Scanning Electron Microscope) images of the microstructure of glass fiber surface and cement matrix. It can be seen from Figure 5(a) that glass fiber surface has been covered with the cement matrix. This phenomenon indicates a bond between the glass fiber and mortar. However, there are voids between fibers and matrix and the interface layer of the mortar is quite loose. The SEM micrograph shown in Figure 5(b) specifies that the glass fiber pulled out from the cement matrix presents a smooth surface. This indicates that a debonding between cement matrix and glass fiber may occur in some areas of the cement mortar. This event may also result in a decrease in compressive strength of the glass fiber reinforced mortar specimens.

In general, as can be clearly concluded from 
Table 6. Results of mechanical and physical tests of the specimens.

\begin{tabular}{lcccc}
\hline Specimens & $\begin{array}{c}\text { Compressive } \\
\text { strength } \\
(\mathbf{M P a})\end{array}$ & $\begin{array}{c}\text { Flexural } \\
\text { strength } \\
\mathbf{( M P a )}\end{array}$ & $\begin{array}{c}\text { Porosity } \\
\mathbf{( \% )}\end{array}$ & $\begin{array}{c}\text { Sorptivity } \\
\text { coefficient } \\
\left.\mathbf{( 1 0}^{-\mathbf{3}} \mathbf{c m . s}^{-\mathbf{1}} \mathbf{2}\right)\end{array}$ \\
\hline C (GF0-MD0) & 84.70 & 11.51 & 17.10 & 0.86 \\
GF0-MD10 & 87.32 & 12.20 & 16.91 & 0.80 \\
GF0-MD30 & 93.41 & 12.74 & 16.65 & 0.74 \\
GF0-MD50 & 96.83 & 13.24 & 16.42 & 0.54 \\
GF0.25-MD0 & 82.73 & 11.84 & 17.35 & 1.13 \\
GF0.25-MD10 & 84.07 & 12.53 & 17.29 & 1.06 \\
GF0.25-MD30 & 87.09 & 13.00 & 17.11 & 0.92 \\
GF0.25-MD50 & 92.64 & 13.50 & 16.86 & 0.85 \\
GF0.50-MD0 & 81.77 & 12.32 & 17.69 & 1.30 \\
GF0.50-MD10 & 83.16 & 12.71 & 17.56 & 1.26 \\
GF0.50-MD30 & 86.45 & 13.27 & 17.29 & 1.08 \\
GF0.50-MD50 & 90.15 & 13.76 & 17.15 & 1.02 \\
GF0.75-MD0 & 79.97 & 12.57 & 17.82 & 1.42 \\
GF0.75-MD10 & 81.11 & 13.09 & 17.68 & 1.29 \\
GF0.75-MD30 & 84.91 & 13.59 & 17.46 & 1.21 \\
GF0.75-MD50 & 88.65 & 13.98 & 17.24 & 1.15 \\
\hline
\end{tabular}

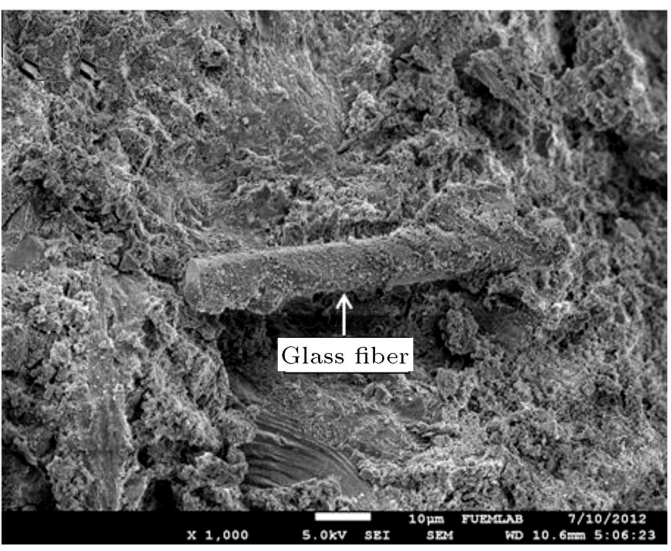

(a)

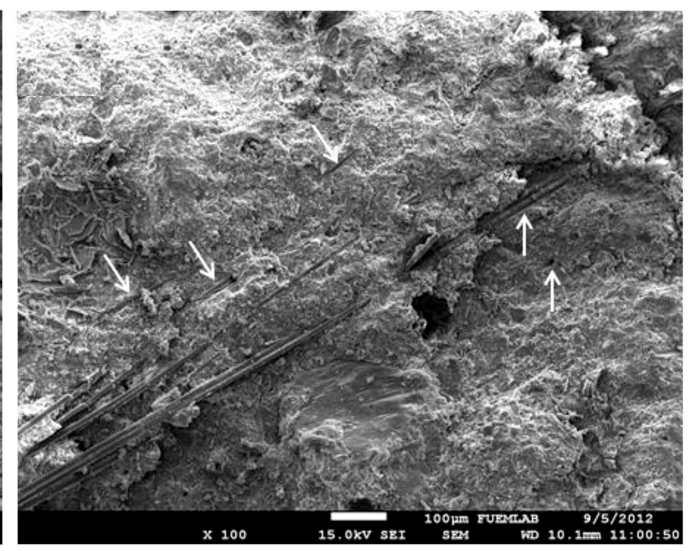

(b)

Figure 5. SEM images of the glass fibers in the cement mortar.

Table 6 , in contrast to compressive strength compared with the control specimen, the glass fiber reinforcement increased the flexural strength of the cement mortar specimens. Previous studies have reported that the addition of fiber into cement based materials can significantly improve flexural strength of the specimens [2830]. This may be attributed to the fact that after the flexural cracking of the glass fiber reinforced mortar specimens, the stress is transferred to the bridging fibers, and thus the development of macro-cracks is delayed and flexural strength of the mortar specimens is increased. These observations are in good agreement with earlier findings [26-28,31,32].

It was also observed that the control mortar specimen showed brittle behavior. When subjected to the flexural loading, the control specimen was broken into two parts once a bending crack occurred. But, the addition of the glass fiber effectively slowed down the propagation of the cracks, and therefore flexural strength of the mortar specimen increased.

The addition of marble dust as very fine sand into cement mortar specimens with and without glass fiber resulted in an increase in the compressive and flexural strengths. This result may have one underlying reason; the reason is that the marble dust has a much small grain size compared to very fine sand, enabling it to fill in the voids. The fineness of an admixture is highly critical for the modification of aggregate/cement 


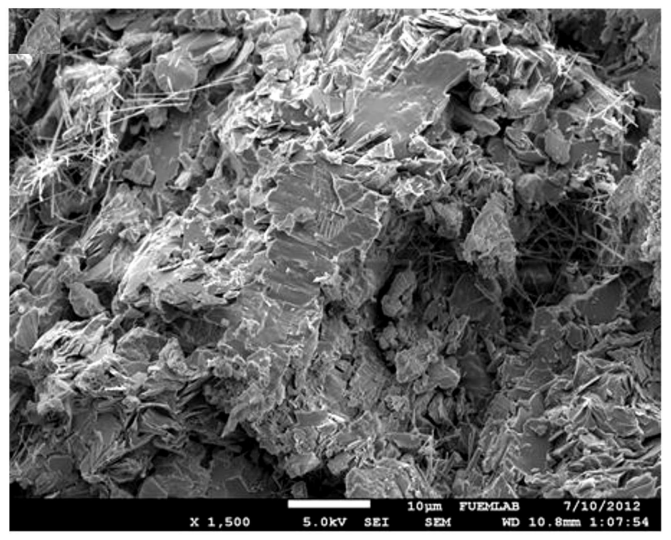

(a)

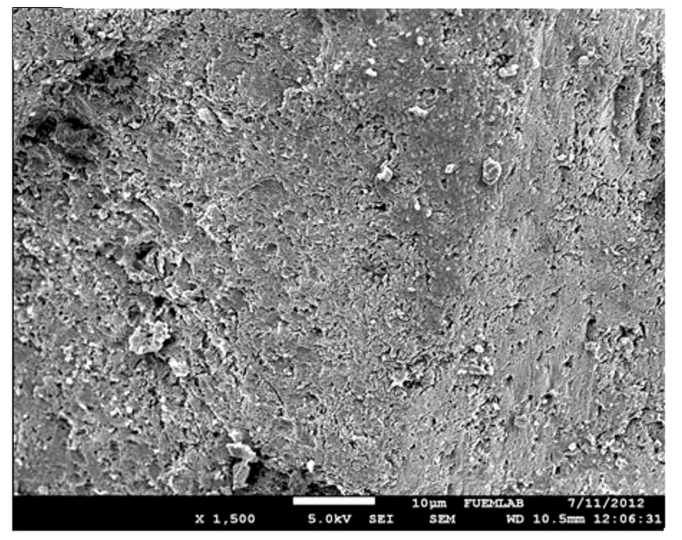

(b)

Figure 6. SEM micrographs of a) control and b) GF0-MD50 mortar specimens.

paste interface zone, which is the weakest link of a concrete's structure [33]. It can be seen clearly from Figure 2 that average particle size of the very fine sand is very large compared to marble dust, therefore its filler effect may not be sufficient as marble dust. It can be concluded that compressive and flexural strengths of the mortars without marble dust are relatively low, because the filler effect of the very fine sand is not as good as that of marble dust. The marble dust particles, however, may act as ideal micro fine filler in the interfaces between aggregate and cement paste or pores in the bulk paste. This filler effect improves the cement matrix and transition zone properties. Thus, high levels of compressive and flexural strengths are achieved in the mortars with marble dust compared to that of the only glass fiber reinforced mortars. These observations agreed fairly well with those obtained by other researchers $[1,7,34,35]$.

Table 6 shows the change of porosity values of the cement mortar specimens. From this table, it can be seen that the glass fiber reinforced mortar specimens showed the highest percentage of porosity. This can be explained by the redistribution of the void structure due to the inclusion of glass fibers.

It can be seen from Table 6 that the addition of glass fiber into mortar mixture significantly increased the sorptivity coefficient. This may be due to distribution of the glass fibers and the increased porosity in the cement paste in the contact zone close to the fibers. Similar relationship has also been noticed by other researchers [36,37].

From Table 6, it can be seen that the usage of marble dust as a partial replacement of very fine sand showed a decrease in porosity value and sorptivity coefficient of the mortar specimens. This decrease could be explained as a result of the pore-filling effect of fine marble dust that improves the properties of the transition zone surrounding fiber and aggregate. The filler effect of marble dust has also been reported by the other researchers $[1,7,34]$.
A number of SEM micrographs that illustrate the micro-structure characteristics of some cement mortar specimens are shown in Figure 6. During scanning process, it was observed that marble dust blended cement mortar specimens were denser and less porous than the control specimen. The control and glass fiber reinforced mortars have larger capillary pores and possess lower compressive strength, which results in the higher capillary sorption in these mortars. Since marble dust is very fine, pores in the bulk paste or in the interfaces between glass fiber and mortar are filled by this admixture. Therefore, the capillary pores are reduced in the mortars containing marble dust. The beneficial role of the marble dust causes an increase in the mechanical strength and a reduction in the capillary sorption of the mortars with and without glass fiber. This finding is in good agreement with the previous study reported by Demirel [7].

\subsection{Results of corrosion experiments}

The results obtained from corrosion potential measurements of reinforcing steel embedded in the mortar specimens containing marble dust and glass fiber in various combinations are shown in Figures 7-11.

As seen in Figure 7, the electronegative corrosion potential is much more in all the glass fiber reinforced

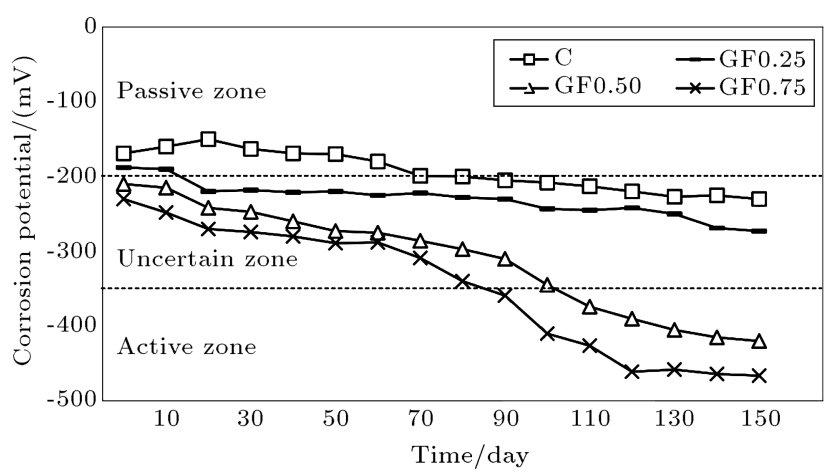

Figure 7. Corrosion potentials of the C, GF0.25, GF0.50, and GF0.75 specimens. 


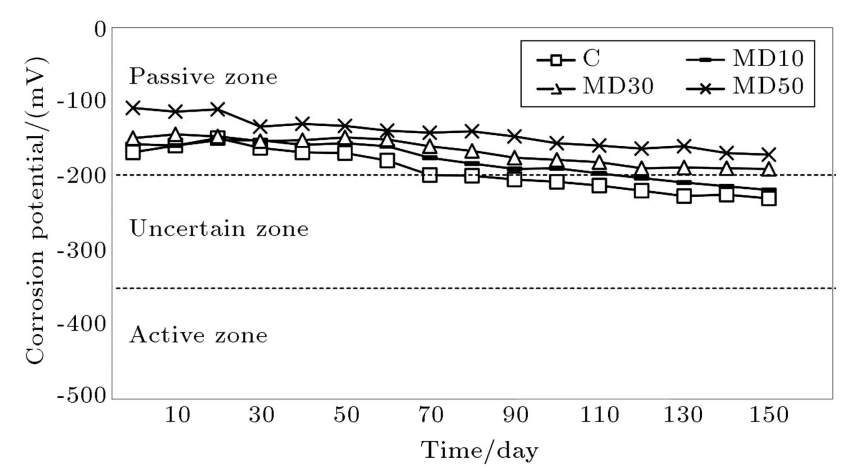

Figure 8. Corrosion potentials of the C, MD10, MD30, and MD50 specimens.

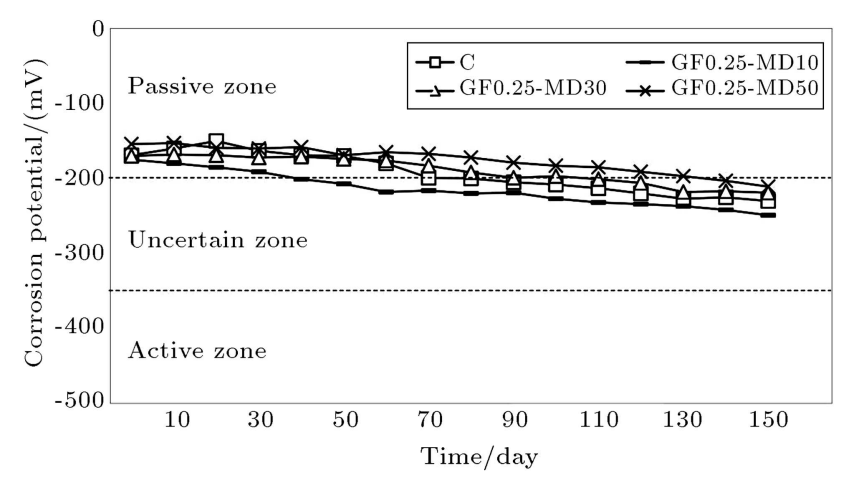

Figure 9. Corrosion potentials of the C, GF0.25-MD10, GF0.25-MD30, and GF0.25-MD50 specimens.

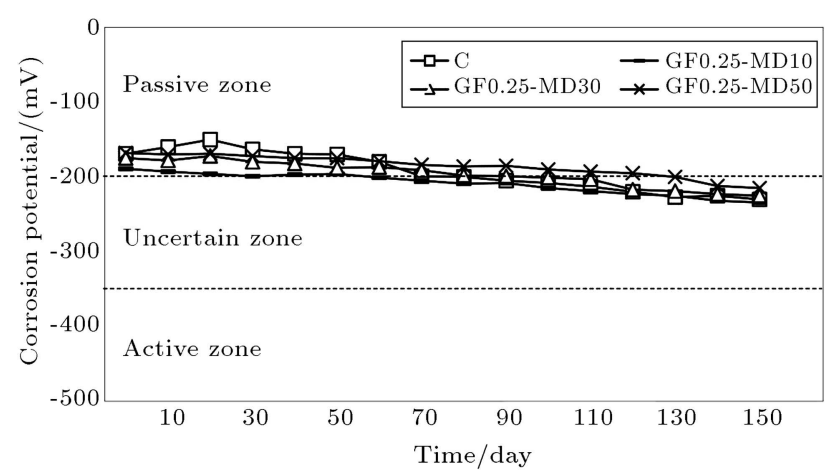

Figure 10. Corrosion potentials of the C, GF0.50-MD10, GF0.50-MD30, and GF0.50-MD50 specimens.

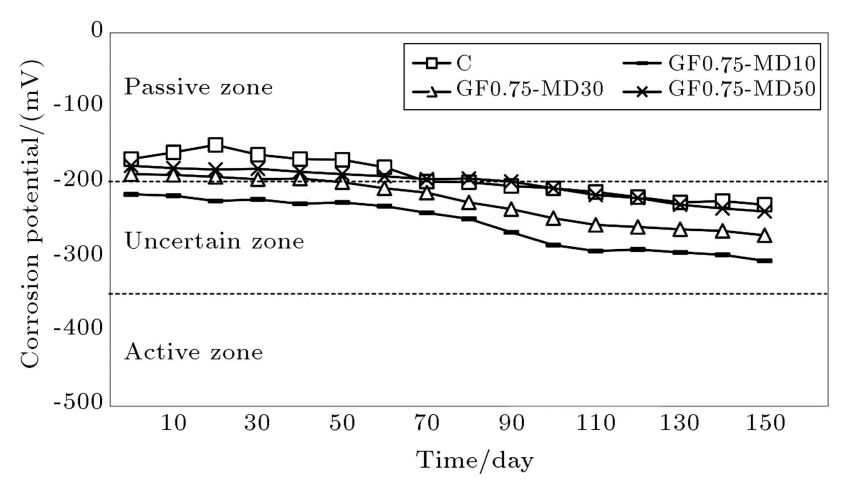

Figure 11. Corrosion potentials of the C, GF0.75-MD10, GF0.75-MD30, and GF0.75-MD50 specimens. mortar specimens of any type than that in the control specimen. Large increases were observed in electronegative corrosion potential when the glass fiber amount was increased. Indeed, the electrodes in the control specimen became more passive than those in the glass fiber reinforced specimens and they remained in the passive zone in terms of corrosion during the 70 days period. Then, the corrosion potentials of the electrodes in the control specimen entered the uncertain zone and stabilized afterwards. The corrosion potentials of the reinforcing steels embedded in GF0.25 specimen reached the uncertain zone after the 2nd week and remained there for all the remaining duration of the test. GF0.50 and GF0.75 mortar specimens, which possess the highest electronegative corrosion potential, reached the active zone after the $3 \mathrm{rd}$ month and remained there until the end of the 150th day. By taking ASTM C876 as a reference, these observations were concluded to indicate that the corrosion still continued in the GF0.50 and GF0.75 specimens even at the end of the 150th day. The GF0.75 specimen has the lowest corrosion resistance among the glass fiber reinforced mortar specimens. By taking account of the results of corrosion potentials by ASTM C876 standard, it can be remarked that the control mortar specimen has higher corrosion resistance than the mortar specimens containing glass fiber in various amounts.

As clearly seen from Figures 8-11, marble dust addition increased the passivation rate of reinforcing steels embedded in the mortar specimens with and without glass fiber. In fact, the reinforcing steels in the specimens with only marble dust (MD10, MD30, and MD50) became more passive compared to the $\mathrm{C}$ specimen and remained in the passive zone in terms of corrosion during the 150 days test period. The passivation rate of the steels in the mortars with marble dust increased depending on the increase in the percentage of marble dust. Furthermore, marble dust increased the passivation rate of the steel bars in the glass fiber reinforced mortars. So that, the glass fiber reinforced mortars of any type remained in the uncertain zone even at the 150th day. These situations are an indication of that; while the corrosion resistance of a mortar is reduced by adding glass fiber, it increases again as marble dust is added to those mortars containing glass fiber. The addition of marble dust such that it would replace with very fine sand in various proportions in mortars consisting of glass fiber up to $0.75 \mathrm{~kg} / \mathrm{m}^{3}$ (GF0.25, GF0.50, and GF0.75) has enhanced the corrosion resistance of the mortar specimens and carried some glass fiber reinforced specimens (GF0.25-MD50, GF0.25-MD30, and GF0.50-MD50) above that of the $\mathrm{C}$ specimen.

The corrosion potential measurement provides qualitative observations and probably points out the corrosion of reinforcing steel bar embedded in mortar to 


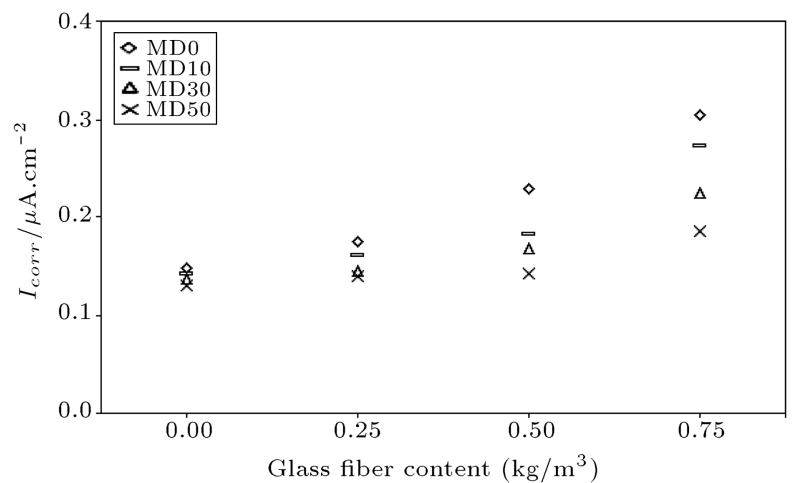

Figure 12. Changes in the $I_{\text {corr }}$ of the mortar specimens.

a large extent. On the other hand, reliable quantitative data on the corrosion of steel bar embedded in mortar specimen can be obtained by measuring resistance or current density of the steel.

Results of corrosion polarization studies on the developed mortar specimens with respect to copper sulfate electrode are shown in Figure 12. The data of corrosion current density $\left(I_{\text {corr }}\right)$ shown in Figure 12 has been derived from the experimentally obtained cathodic polarization curves using Tafel's linear extrapolation method.

The corrosion current density values seem to confirm the corrosion potential values. As is clearly seen in Figure 12, the $\mathrm{C}$ specimen exhibits the highest corrosion resistance compared to the mortar specimens produced with only glass fiber. Furthermore, corrosion resistance has decreased in parallel to the increase in volume fraction of glass fiber in the mortar specimen. This decrease in corrosion of the specimens results from the voids between the glass fibers and matrix. As it is known, oxygen input into the mortar is facilitated at higher porosities. An increase in oxygen concentration increases the current density and corrosion rate of the specimen. Thus, the corrosion resistance of the mortar specimens with glass fiber drops off since the oxygen input increases due to the voids emerging after the glass fiber addition. As seen in Figure 12, however, the corrosion resistance of the mortar specimens has been increased as a result of marble dust addition to the mortars with and without glass fiber. As already specified, it is attributed to the fact that in the $\mathrm{C}$ mortar, the average particle size of the very fine sand is higher than the specimens with marble dust and the pores in bulk paste and interfaces are not filled completely. The fine particles result in a relatively dense structure and more discontinuous pores in the cement mortar. It also reduces the volume of large voids and capillaries. The resultant cement matrix is more chemically resistant, and it has a denser microscopic pore structure and a relatively impermeable mortar specimen. Table 6 shows that cement mortars containing marble dust demonstrate the lowest water absorption ability and porosity among all the mortar specimens studied in this work. Water normally enters the mortar through capillary action; the fewer and smaller the capillary pores are, the less water enters the mortar and the lower the rates of oxygen diffusion. Due to the high alkalinity in cement mortar, there are very few $\mathrm{H}+$ ions to be consumed in the cathodic reaction, so that the oxygen has to be reduced in order to sustain the cathodic reaction. Therefore, when the oxygen reduction rate falls, so does the corrosion rate. Chloride ions tend to eliminate the normal passivation state of reinforcing steel bars in mortar. Low air void contents and low water absorptivity help keep chloride ions in going through the mortar and reaching the surface of the steel bars [33,38]. Hereby, a mortar containing marble dust, which has a denser microscopic pore structure, is relatively impermeable to chloride ions. Thus, in this study, addition of the marble dust as very fine sand into the mortars with and without glass fiber effectively increased the corrosion resistance of the specimens which were submerged in chloride solutions.

\section{Conclusions}

On the basis of experimental study that has been carried out and presented in this paper, the following conclusions can be drawn:

1. When marble dust was added to the mortar specimens with and without glass fiber, it improved both the mechanical strength and other performance parameters (porosity and sorptivity values). This finding is due to the fact that marble dust particles may act as ideal micro filler in the interfaces between glass fiber and mortar or pores in the bulk paste;

2. In contrast to marble dust effect, the use of glass fiber in the cement mortars increased the flexural strength, porosity, and sorptivity values, but decreased the compressive strength of the specimens. The reduction in the compressive strength and rise in the porosity and sorptivity values of the mortars can be attributed to the voids between the glass fiber and mortar. Furthermore, glass fibers give rise to discontinuity in the cement matrix due to their more ductile structure than that of the cement matrix;

3. As a result of the experiments conducted for the purpose of determining the corrosion resistance of glass fiber reinforced mortars, it has been observed that the corrosion resistance of the specimens decreases in line with increasing amount of glass fiber. However, addition of the marble dust as very fine sand into the glass fiber reinforces mortar specimens and significantly increases the corrosion resistance of these specimens; 
4. The experimental findings indicate that the addition of the marble dust in a way that it would replace the very fine sand at proportions of $10 \%$, $30 \%$, and $50 \%$ by volume into the mortars without glass fiber has reduced the corrosion rate of the steel electrodes embedded in these mortars to even lower levels than that of the electrodes in the control mortar.

\section{References}

1. Aliabdo, A.A., Elmoaty, M.A. and Auda, E.M. "Reuse of waste marble dust in the production of cement and concrete", Const. Build. Mat., 50, pp. 28-41 (2014).

2. Karaşahin, M. and Terzi, S. "Evaluation of marble waste dust in the mixture of asphaltic concrete", Const. Build. Mat., 21, pp. 616-620 (2007).

3. Yıilmaz, H., Gürü, M., Dayı, M. and Tekin, I. "Utilization of waste marble dust as an additive in cement production", Mater Des., 31, pp. 4039-42 (2010).

4. Corinaldesi, V., Moriconi, G. and Naik, T.R. "Characterization of marble powder for its use in mortar and concrete", Const. Build. Mat., 24, pp. 113-7 (2010).

5. Binici, H., Kaplan, H. and Yilmaz, S. "Influence of marble and limestone dusts as additives on some mechanical properties of concrete", Sci. Res. Essay., 2(9), pp. 372-9 (2007).

6. Ergün, A. "Effects of the usage of diatomite and waste marble powder as partial replacement of cement on the mechanical properties of concrete", Const. Build. Mat., 25, pp. 806-12 (2011).

7. Demirel, B. "The effect of the using waste marble dust as fine sand on the mechanical properties of the concrete", Int. J. Phys. Sci., 5(9), pp. 1372-1380 (2010).

8. Kelecstemur, O., Arıcı, E., Yıldız, S. and Gökçer, B. "Performance evaluation of cement mortars containing marble dust and glass fiber exposed to high temperature by using Taguchi method", Const. Build. Mat., 60, pp. 17-24 (2014).

9. Keleştemur, O., Yıldız, S., Gökçer, B. and Arıcı, E. "Statistical analysis for freeze-thaw resistance of cement mortars containing marble dust and glass fiber", Mater. Design, 60, pp. 548-555 (2014).

10. Emiroglu, M., Beycioglu, A. and Yildiz, S. "ANFIS and statistical based approach to prediction the peak pressure load of concrete pipes including glass fiber", Exp. Syst. with Applica., 39, pp. 2877-2883 (2012).

11. Asokan, P., Osmani, M. and Price, A.D.F. "Assessing the recycling potential of glass fiber reinforced plastic waste in concrete and cement composites", J. Clean. Product., 17, pp. 821-829 (2009).

12. Asokan, P., Osmani, M. and Price, A.D.F. "Improvement of the mechanical properties of glass fibre reinforced plastic waste powder filled concrete", Const. Build. Mat., 24, pp. 448-460 (2010).
13. Bai, W., Zhang, J., Yan, P. and Wang, X. "Study on vibration alleviating properties of glass fiber reinforced polymer concrete through orthogonal tests", Mater. Design, 30, pp. 1417-1421 (2009).

14. Sideris, K.K. and Savva, A.E. "Durability of mixtures containing calcium nitrite based corrosion inhibitor", Cem. Conc. Comp., 27(2), pp. 277-287 (2005).

15. Gonzalez, J.A., Molina, A., Otero, E. and Lopez, W. "On the mechanism of steel corrosion in concrete: The role of oxygen diffusion", Mag. Conc. Res., 42(150), pp. 23-27 (1990).

16. ASTM C876-91, Standard Test Method for Half-Cell Potentials of Uncoated Reinforcing Steel in Concrete, ASTM International, West Conshohocken, PA (1999).

17. Keleştemur, O., Aksoy, M., Yıldız, S. "Corrosion behavior of tempered dual-phase steel embedded in concrete", Int. J. Miner. Metall. Mater., 16(1) pp. 4350 (2009).

18. Keleştemur, O. and Yıldız, S. "Effect of various dualphase heat treatments on the corrosion behavior of reinforcing steel used in the reinforced concrete structures", Const. Build. Mat., 23, pp. 78-84 (2009).

19. Mydin, M.A.O. "Modeling of transient heat transfer in foamed concrete slab", J. Eng. Sci. Tech., 8(3), pp. 326-343 (2013).

20. Cabrera, J.G. and Lynsdale, C.J. "A new gas permeameter for measuring the permeability of mortar and concrete", Mag. Conc. Res., 40(144), pp. 177-182 (1988).

21. Gonen, T. and Yazicioglu, S. "The influence of mineral admixtures on the short and long-term performance of concrete", Build. Env., 42, pp. 3080-3085 (2007).

22. Gonen, T. and Yazicioglu, S. "The influence of compaction pores on sorptivity and carbonation of concrete", Const. Build. Mat., 21, pp. 1040-1045 (2007).

23. Tasdemir, C. "Combined effects of mineral admixtures and curing conditions on the sorptivity coefficient of concrete", Cem. Conc. Res., 33, pp. 1637-1642 (2003).

24. Turkmen, I. "Influence of different curing conditions on the physical and mechanical properties of concretes with admixtures of silica fume and blast furnace slag", Mat. Lett., 57(29), pp. 4560-4569 (2003).

25. Demirel, B. and Keleştemur, O. "Effect of elevated temperature on the mechanical properties of concrete produced with finely ground pumice and silica fume", Fire Safe. J., 45, pp. 385-391 (2010).

26. Çavdar, A. "A study on the effects of high temperature on mechanical properties of fiber reinforced cementitious composites", Compos. B., 43, pp. 2452-2463 (2012).

27. Çavdar, A. "Investigation of freze-thaw effects on mechanical properties of fiber reinforced cement mortars", Compos. B., 58, pp. 463-472 (2014).

28. Jiang, C., Fan, K., Wu, F. and Chen, D. "Experimental study on the mechanical properties and microstructure 
of chopped basalt fibre reinforced concrete", Mater. Des., 58, pp. 187-193 (2014).

29. Sivakumar, A. and Santhanam, M. "Mechanical properties of high strength concrete reinforced with metallic and non-metallic fibres", Cem. Conc. Comp., 29(8), pp. 603-608 (2007).

30. Song, P.S. and Hwang, S. "Mechanical properties of high-strength steel fiber-reinforced concrete", Const. Build. Mat., 18(9), pp. 669-673 (2004).

31. Qureshi, L.A. and Ahmed, A. "An investigation on strength properties of glass fiber reinforced concrete", Int. J. Eng. Res. Tech., 2(4), pp. 2567-2572 (2013).

32. Kene, K.S., Vairagade, V.S. and Sathawane, S. "Experimental study on behavior of steel and glass fiber reinforced concrete composites", Bonfring Int. J. Indust. Eng. Manag. Sci., 2(4), pp. 125-130 (2012).

33. Keleştemur, O. and Demirel, B. "Corrosion behavior of reinforcing steel embedded in concrete produced with finely ground pumice and silica fume", Const. Build. Mat., 24, pp. 1898-1905 (2010).

34. Kristulovic, P., Kamenic, N. and Popovic, K. "A new approach in evaluation of filler effect in cement", Cem. Conc. Res., 24(4), pp. 721-727 (1994).

35. Topcu, I.B., Bilir, T. and Uygunoglu, T. "Effect of waste marble dust content as filler on properties of self-compacting concrete", Const. Build. Mat., 23(5), pp. 1947-1953 (2009).
36. Duran Atiş, C. and Karahan, O. "The durability properties of polypropylene fiber reinforced fly ash concrete", Mater. Des., 32, pp. 1044-1049 (2011).

37. Duran Atiş, C. and Karahan, O. "Properties of steel fiber reinforced fly ash concrete", Const. Build. Mat., 23, pp. 392-399 (2009).

38. Hou, J. and Chung, D.D.L. "Effect of admixtures in concrete on the corrosion resistance of steel-reinforced concrete", Corros. Sci., 42, pp. 1489-1507 (2000).

\section{Biographies}

Ŏguzhan Keleştemur received his MS and PhD degrees in Construction Education from Firat University, Turkey, in 2003 and 2008. He is currently Associate Professor in the Civil Engineering Department of the Technology Faculty at Firat University. His research interests include: concrete, corrosion, dual-phase steel, construction materials.

Servet Yıldız received his $\mathrm{MS}$ and $\mathrm{PhD}$ degrees in Civil Engineering from Firat University, Turkey, in 1989 and 1998. He is currently Associate Professor in the Civil Engineering Department of the Technology Faculty at Firat University. He currently serves as Vocational School Manager at Firat University. His research interests include: concrete, construction materials. 